\title{
Review on the epidemiology and dynamics of BSE epidemics
}

\author{
Christian Ducrot ${ }^{1 *}$, Mark ARnOLD ${ }^{2}$, Aline DE KoEIJER ${ }^{3}$, Dagmar HeIM $^{4}$, \\ Didier CALAVAS ${ }^{5}$ \\ ${ }^{1}$ INRA Unité d'Épidémiologie Animale, 63122 Saint-Genès-Champanelle, France \\ 2 VLA Sutton Bonington, The Elms, College Road, Sutton Bonington, Loughborough, LE12 5RB, England \\ ${ }^{3}$ Division of Infectious Diseases, Animal Sciences Group, Wageningen, University and Research Center, \\ PO Box 65, 8200 AB Lelystad, The Netherlands \\ ${ }^{4}$ Office vétérinaire fédéral, Schwarzenburgstrasse 155, Case Postale 3003, Bern, Suisse \\ ${ }^{5}$ AFSSA Lyon, Unité Épidémiologie, 31 avenue Tony Garnier, 69364 Lyon Cedex 07, France
}

(Received 24 April 2007; accepted 23 October 2007)

\begin{abstract}
The paper describes how the comprehensive surveillance of bovine spongiform encephalopathy (BSE) and studies carried out on these data has enhanced our knowledge of the epidemiology of BSE. Around 7000 BSE cases were detected through the screening of about 50 million cattle with rapid tests in Europe. It confirmed that the clinical surveillance had a poor capacity to detect cases, and also showed the discrepancy of this passive surveillance efficiency between regions and production types (dairy/beef). Other risk factors for BSE were being in a dairy herd (three times more than beef), having a young age at first calving (for dairy cattle), being autumn-born (dairy and beef), and being in a herd with a very high milk yield. These findings focus the risk on the feeding regimen of calves/heifers. Several epidemiological studies across countries suggest that the feedborne source related to meat and bone meal (MBM) is the only substantiated route of infection - even after the feed ban - , while it is not possible to exclude maternal transmission or milk replacers as a source of some infections. In most European countries, the average age of the cases is increasing over time and the prevalence decreasing, which reflects the effectiveness of control measures. Consistent results on the trend of the epidemic were obtained using back-calculation modelling, the $R_{0}$ approach and Age-Period-Cohort models. Furthermore, active surveillance also resulted in the finding of atypical cases. These are distinct from previously found BSE and classified in two different forms based on biochemical characteristics; their prevalence is very low (36 cases up to 1st September 2007), affected animals were old and some of them displayed clinical signs. The origin and possibility of natural transmission is unknown.
\end{abstract}

\section{BSE / epidemiology / modelling / review / control}

Table of contents

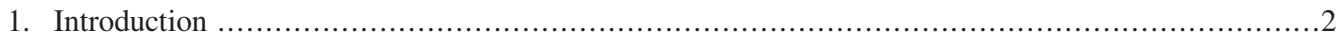

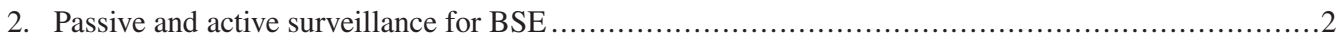

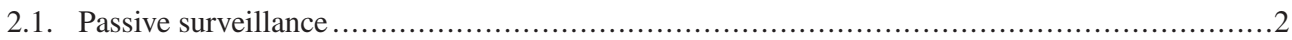

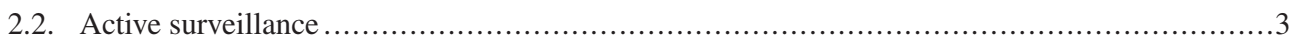

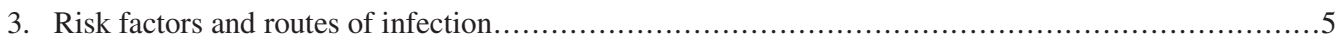

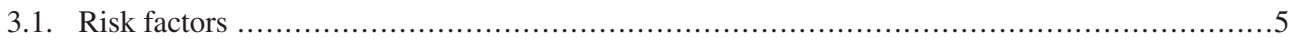

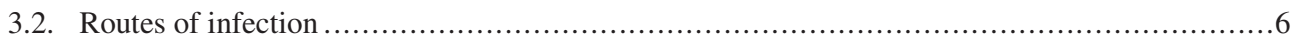

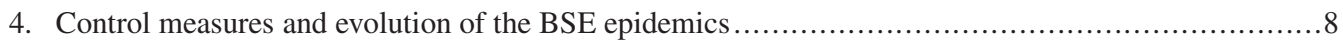

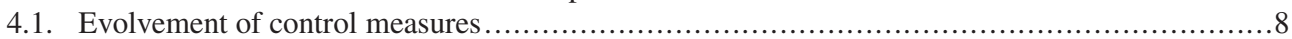

4.2. Evolution of the BSE epidemic analysed from modelling and age of cases......................

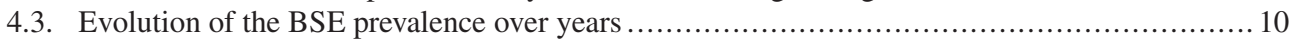

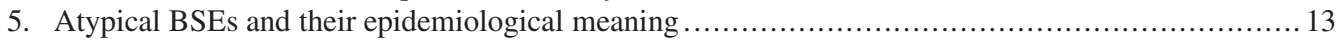

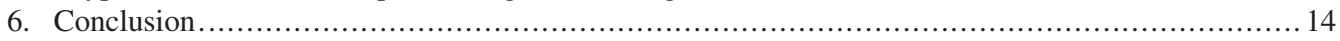

*Corresponding author: ducrot@ clermont.inra.fr 


\section{INTRODUCTION}

In April 1985 the first case of a disease was observed in Great Britain that would later be described as BSE. It was characterised by slowly progressive neurological disorders of adult cattle [62], always lethal, with various and inconstant clinical signs related to mental status, sensation, posture and movement, as well as body loss and reduced milk yield, that were precisely described by Cranwell et al. [22] and Wilesmith et al. [64]. Based on pathology changes, that were characterized by brain stem grey matter vacuolisation and scrapie associated fibrils, pathologists evidenced a spongiform encephalopathy [62] and the first transmission to mice was published in 1988 [35]. In an early stage, epidemiology took an important part in the understanding of the disease, through different studies carried out by Wilesmith et al. [64-66] that evidenced the role of meat and bone meal (MBM) as the major route of infection. This led to control measures implemented in 1988 in the United Kingdom (UK) and subsequently in the European Union (EU) to reduce the exposure of cattle to MBM. They had a great effect in decreasing the epidemic, which was strongly observed in the UK [38], but were not fully effective in controlling the disease, so that further measures were taken. In the nineties, modelling studies were carried out on the British data [4] that estimated retrospectively the size of the epidemic and the key parameters of it, such as the age at infection and the incubation time. In the ten years since the initial modelling, new diagnostic tools have been developed and widely used in the EU; through a comprehensive active surveillance, the disease has been discovered in many countries, and a large amount of work has been done by different teams in the field of epidemiology and modelling.

The aim of this paper is to present how these new data and further studies have enhanced our knowledge of the epidemiology of BSE. We explain how the wide use of screening tests has changed our view of the descriptive epidemiology of BSE, what was learnt concerning risk factors and routes of infection, and how the BSE epidemic behaved as a re- sult of new control measures. Then we address the question of atypical forms of BSE found as a result of intensive surveillance and we draw some provisional conclusions in relation to surveillance and control of BSE for the future.

\section{PASSIVE AND ACTIVE SURVEILLANCE FOR BSE}

\subsection{Passive surveillance}

By the beginning of 2000, only 9 out of 25 countries that have now reported BSE cases, had detected BSE cases in the domestic cattle population ${ }^{1}$. This large increase in the number of countries with reported BSE cases since 2000 was mainly based on the introduction of an extensive active surveillance system. While a passive surveillance system is based on the reporting of clinical suspect cases to the veterinary authorities by veterinarians, with active surveillance, statistically representative numbers of animals are identified from defined target populations and these animals are tested for the disease [28,61]. Before 2001, only passive surveillance was implemented in most of these countries, which depended entirely on the mandatory reporting of clinically suspect cattle by farmers, veterinarians, and others involved in handling cattle, and the follow-up of these animals by government veterinary services.

Passive surveillance in general is assumed to be effective whenever the disease is highly contagious, has a short incubation period, and the clinical signs are easy to recognise [28]. These characteristics are not fulfilled in the case of BSE, where usually only one animal per herd is affected and the incubation period is on average more than five years. Also, there is a misconception that BSE is easy to recognise, as the clinical signs of BSE in cattle are variable, often subtle, and not pathognomonic [11, 18,44]. Additionally, the willingness to report suspected cases of BSE was

\footnotetext{
${ }^{1}$ European Commission (2002), Report on the monitoring and testing of bovine animals for the presence of bovine spongiform encephalopathy (BSE) in 2001, http://europa.eu.int/comm/food/food/biosafety/bse/ bse45_en.pdf [consulted 2 April 2007].
} 
and is often low; this is due to low compensation for suspected and/or confirmed cases, to the consequences of a positive diagnosis and subsequent control measures, which are often not considered to be reasonable by cattle owners, and to the stigmatization of cattle owners - especially if they have the first case in the country. The quality of these passive surveillance systems differed from country to country and the results were not easy comparable.

\subsection{Active surveillance}

Because results of passive surveillance did not allow the true BSE prevalence to be estimated, in January 1999, Switzerland initiated an active, targeted surveillance scheme to enhance the detection of BSE cases in the adult cattle population $[27,29]$. In addition to the passive surveillance system, all cattle in the entire risk population (i.e., all cattle that have died or been killed on farm or during transport, fallen stock, and cattle sent to emergency/sick slaughter) over 24 months of age were tested. Additionally, approximately $3 \%$ of the total number of adult cattle sent to routine slaughter were randomly sampled and tested, to minimise diversion of suspected BSE cases to routine slaughter. In spring 2000, France initiated also the testing of the risk population in several regions considered at higher risk of BSE given the results of passive surveillance [15]. Based on these results, the EU introduced active screening in risk populations for BSE in January 2001, and expanded the surveillance to all cattle subject to routine slaughter over 30 months of age (in some countries also younger animals) to be implemented at latest in July $2001^{1}$.

Through the introduction of active surveillance, countries which claimed for years to have no BSE cases detected their first cases. Furthermore the incidence per million cattle alive increased significantly in countries which had already detected BSE cases before the start of active surveillance (Fig. 1). These unbiased surveillance data showed that most EU countries did indeed have a low incidence of BSE, which was already indicated by the results of the geographical BSE risk assessment
$(\mathrm{GBR})^{2}$. The GBR, which had been initiated in 1998 to assess the risk of having BSE for various countries as a basis for trade and food safety, was in fact very effective in estimating the BSE risk. Most countries that had been assessed into category III (likely a low level of BSE present) did indeed find at least a few cases of BSE through the active surveillance. From 2001 to 2005, a total of around 50 million cattle have been tested in the framework of the surveillance program in the EU, of which around 7000 cases proved BSEpositive (Tab. I) $)^{1,3,4,5,6}$. The youngest case of BSE to date was found by passive surveillance in the $\mathrm{UK}^{7}$ and was 20 months old. In the framework of the active surveillance system in the EU only two animals below 30 months of

\footnotetext{
${ }^{2}$ Scientific Steering Committee (2000), Final opinion of the scientific steering committee on the geographical risk of bovine spongiform encephalopathy (GBR), http://europa.eu.int/ comm/food/fs/sc/ssc/out113_en.pdf [consulted 2 April 2007].

${ }^{3}$ European Commission (2003), Report on the monitoring and testing of ruminants for the presence of transmissible spongiform encephalopathy (TSE) in 2002: http://europa.eu.int/ comm/food/food/biosafety/bse/annual_report_2002 _en.pdf [consulted 2 April 2007].

${ }^{4}$ European Commission (2004), Report on the monitoring and testing of ruminants for the presence of transmissible spongiform encephalopathy (TSE) in the EU in 2003, including the results of the survey of prion protein genotypes in sheep breeds, http://europa.eu.int/comm/food/food/biosafety/bse/ annual_report_tse2003_en.pdf [consulted 2 April 2007].
}

${ }^{5}$ European Commission (2005), Report on the monitoring and testing of ruminants for the presence of transmissible spongiform encephalopathy (TSE) in the EU in 2004, http://ec.europa.eu/food/food/biosafety/bse/annual_ report_tse2004_en.pdf [consulted 2 April 2007].

${ }^{6}$ European Commission (2006), Report on the monitoring and testing of ruminants for the presence of transmissible spongiform encephalopathy (TSE) in the EU in 2005, http://ec.europa.eu/food/food/biosafety/bse/annual_ report_tse2005_en.pdf [consulted 2 April 2007].

${ }^{7}$ http://www.defra.gov.uk/animalh/bse/statistics/bse/ yng-old.html, [consulted 4 April 2007]. 


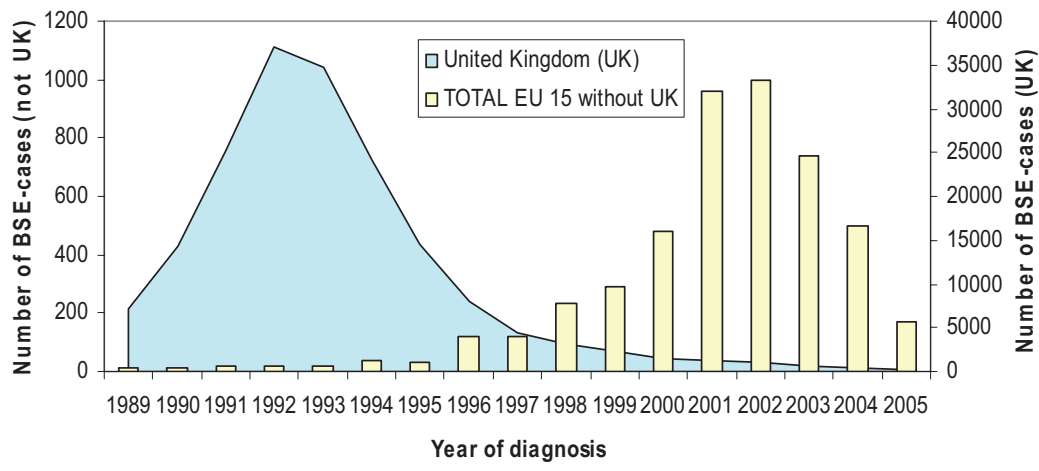

Figure 1. Number of BSE cases in the European Union, 1989-2005. Source European Commission, 2002 to 2006. Reports on the monitoring and testing of ruminants for the presence of transmissible spongiform encephalopathy (TSE) in the EU. http://ec.europa.eu/food/food/biosafety/bse/ [consulted 2 April 2007].

Table I. Number of bovines tested, BSE-positive and prevalence rate in the three surveillance streams, 2001-2005. Source European Commission, 2002 to 2006. Reports on the monitoring and testing of ruminants for the presence of transmissible spongiform encephalopathy (TSE) in the EU (http://ec.europa.eu/food/food/biosafety/bse/ [consulted 2 April 2007]).

\begin{tabular}{lccc}
\hline & Total tested (2001-2005) & Total positive (2001-2005) & $\begin{array}{c}\text { Prevalence rate (positive cases } \\
\text { per 10000 animals tested) }\end{array}$ \\
\hline Risk population* & 6258687 & 3525 & 5.6 \\
Routine slaughter & 43677464 & 1110 & 0.3 \\
Clinical suspects & 15048 & 2320 & 1541.7 \\
Total & 49951199 & 6955 & \\
\hline
\end{tabular}

* Emergency slaughtered, animals with clinical signs at ante-mortem and fallen stock.

age (28 and 29 months) have been detected. Outside the EU, the only country where young cases of BSE have been observed is Japan [71], with two cases with 21 and 23 months of age found by active surveillance. However, there are doubts, whether the two very young cases were adequately identified and formally confirmed ${ }^{8}$.

Although the largest numbers of tested cattle were healthy slaughtered cattle, the majority of positive cases occurred in the suspected cases and risk populations [29, 47, 48]. On average throughout the EU, the likelihood of finding BSE cases is more than 20 times higher in the risk populations than in healthy slaughtered cattle. Passive surveillance is the

\footnotetext{
${ }^{8}$ EFSA (2005), Annex to the opinion of the scientific panel on biological hazards on the assessment of the age limit in cattle for the removal of certain specified risk materials (SRM), The EFSA Journal: $1-21$.
}

most efficient stream - highest ratio positives/suspects - , however with all the limitations discussed above.

Based on the success of the active surveillance in Europe, countries on other continents have also initiated similar surveillance activities with comparable results ${ }^{9,10}[5,59]$. Recommendations for BSE surveillance of the OIE now also include active surveillance ${ }^{11}$. For comparison of surveillance systems among countries, the OIE guidelines

\footnotetext{
${ }^{9}$ http://www.aphis.usda.gov/lpa/issues/bse_testing/ test_results.html [consulted 2 April 2007].

${ }^{10} \mathrm{http}: / /$ www.agr.gc.ca/cb/index_e.php?s1=n\&s2= 2004\&page $=n 41230 \mathrm{~b}$ [consulted 2 April 2007].

${ }^{11}$ OIE (2005), Surveillance systems for bovine spongiform encephalopathy, Appendix 3, 8, 4, Terrestrial animal health code, World Organisation for Animal Health, http://www.oie.int/eng/ normes/mcode/en_chapitre_3.8.4.htm. [consulted 2 April 2007].
} 
assign 'point values' to each sample tested, based on the subpopulation from which it was collected - the lowest value is given for routine slaughter cattle, and the highest value for clinical suspects - and the likelihood of detecting infected cattle in that subpopulation based on the age of animals. All the samples tested are valued according to this guideline and added together. A given number of total points, based on the number of adult cattle in the country and the risk, must be reached to ensure sufficient level of surveillance.

The introduction of active surveillance confirmed the assumed limitations of the passive surveillance systems in identifying and reporting BSE cases. Based on the results of active surveillance it could be demonstrated that the case ascertainment and case reporting levels during the time of passive surveillance were very low [20, 29]. It could be demonstrated through retrospective investigations that more than half of the cases found by active surveillance had displayed clinical signs before death, either characteristic for BSE or at least sufficiently suggestive $[18,29]$. Also, comparing cases found by active and passive surveillance during the same period of time (passive surveillance takes place before death/slaughter) showed biases in the type of animals detected by passive surveillance, the ability to detect beef cow cases being far less efficient than detection of dairy cases [33].

The results of this extended surveillance program in most countries in Europe over several years has enabled comparisons of the prevalence and trend of the BSE epidemic. Also within countries, the development of the epidemic can be constantly analysed, risk factors can be more reliably assessed and predictions of the numbers of future cases can be undertaken.

\section{RISK FACTORS AND ROUTES OF INFECTION}

\subsection{Risk factors}

As explained previously, biases due to clinical surveillance have induced biased estimates of some risk factors at the beginning of the epidemics. The implementation of a comprehensive surveillance based both on clini- cal (passive) surveillance and testing (active surveillance) in most of the European countries since 2001 has enabled a more rigorous analysis of risk factors for BSE.

For example, in both the UK and France it has been identified that dairy cows have a risk of BSE approximately three times higher than that of beef cows, once confounding factors such as age at culling or region of origin have been accounted for $[33,45,68]$. This is simply explained by a higher use of compound feed in dairy farms. However, the difference in risk between dairy and beef cows is not as important as expected if we consider the considerable amount of compound feed fed to dairy cows in lactation compared to the relatively small amount of compound feed used for beef cows. However, this is consistent with an infection at a younger age, when differences in feeding practices (apart from milk supply) are less important between dairy and beef cattle, at least in the French context where it has been studied.

Different studies carried out in the UK showed that autumn-born dairy cattle appeared to be at a higher risk of infection than springborn dairy cattle $[12,39,62,66]$. This has also been confirmed in a recent study carried out in France, which showed that French dairy cows born from July to September were at a higher risk for $\mathrm{BSE}^{12}$. It is most likely that this difference in risk between autumn and spring-born cattle is due to a differential use of concentrates for calves depending on their season of birth. The reason is that the winter period requires feeding in stable, with forage and concentrates, instead of grazing outside. For beef cattle, the same tendency was observed in the French study ${ }^{12}$, with a higher risk for those animals born in August and November, that are supposed to be fed more concentrate feedstuffs and at a younger age.

Further work on the issue of concentrates and risk of infection has been performed by $\mathrm{La}$ Bonnardière et al. [46], who investigated the

\footnotetext{
${ }^{12}$ Sala C., Morignat E., Roy P. et al., Seasonality of exposure of cattle to BSE in France, in Proc. Prion 2006, Strategies, advances and trends towards protection of society, Torino, Italy, 2006, p. 117 (RA-10).
} 
effect of milk yield on the risk of BSE at the farm level in France, since milk yield is highly correlated with the feeding of concentrates for dairy cattle. Accounting for the region of the farm, the year at risk and the herd size, it was found that only the relatively small group of high-yielding herds (above $10000 \mathrm{~kg}$ per lactation on average) had a more than three-fold higher risk than in the least intensive herds (below $7000 \mathrm{~kg}$ ). There was no linear increase in risk as a function of milk yield, because herds from the intermediate classes with a broad range of milk yields (from 7000 to $10000 \mathrm{~kg}$ ) and which accounted for $85 \%$ of the sample, had adjusted odds ratios for milk yield that did not differ significantly. Another factor of interest was the age at first calving, which was found to be correlated to milk yield in that the higher the yield, the younger the age; it appeared that the age at first calving had a specific effect on the risk, irrespective of milk yield.

The herd size could be linked to the risk of BSE for two reasons: firstly, the probability of at least one case in a given herd is size-dependent, and secondly, there are possible herd-size dependent risk factors for BSE, such as certain farming practices. It has been shown in the UK and Ireland that the BSE incidence per animal is higher in large herds, which suggests specific feeding practices in those herds $[32,37]$. However, results are not consistent in all studies. Another epidemiological study, carried out in Northern Ireland, did not find the existence of a herd size effect [26]. La Bonnardière et al. [46] also concluded from French data, that no herd size effect could be detected in addition to the strict mathematical relationship between the number of cattle at risk and their age structure, and the probability of at least one case in a herd.

Many different spatial studies conducted in the last few years have found important differences in risk depending on geographical areas in a given country, even after accounting for confounding factors such as the production type. These geographical differences in risk have been observed in the UK [58], Switzerland [30], France [2], Spain [3], and Ireland [57]. It has also been shown that the spatial risk has moved over time, with a birthcohort dependence [34]. This is likely to be due to spatial heterogeneity in the sources of infection within each country.

\subsection{Routes of infection}

In 1991 it became evident that the ban on MBM in ruminant feed, implemented in July 1988 in the UK, was not totally effective, as cases began to occur in UK animals born after the feed ban (BABs). The occurrence of the BABs attracted much speculation about the natural transmission of BSE between cattle, either maternally or horizontally, since both maternal transmission and horizontal transmission were considered to occur for scrapie in small ruminants [40]. When a sufficient number of BAB cases had occurred in 1993, a case-control study was initiated in the UK to investigate the possibility of horizontal and maternal transmission [39]. This study found rates of maternal transmission consistent with the study results to range between 0 and $13 \%$. Most importantly, the case-control study indicated that neither maternal nor horizontal transmission could account for the majority of cases in animals born after the feed ban. Maternal transmission has also been found to provide a possible explanation for only a minority of cases from several countries after similar feed bans $[41,55]$, and from subsequent data from the UK [69]. Outside UK no BSE in offspring of BSE cases have been found. Modelling studies using data from GB have also shown that maternal transmission, if it does occur, does so at a very low rate; assuming that maternal transmission occurs in the last six months of the incubation period, Donnelly et al. [31] found a rate of maternal transmission of $0.7 \%$ (95\% confidence interval of $0,4.0 \%)$. In the UK, the within-herd incidence has decreased coincidentally with the national incidence and there are a relatively small number of herds that have had a large number of cases and there is therefore no evidence of horizontal transmission of BSE. The low within-herd incidence of herds affected with BSE is also evidence that horizontal transmission does not occur. 
The reasons for the $\mathrm{BAB}$ cases, albeit at a reduced level compared to animals born before the feed ban, started to be identified in GB with analysis of the geographical variation in incidence. A geographical analysis of the incidence of BAB cases showed a statistically significant correlation between the cumulative incidence of $\mathrm{BAB}$ cases and the ratios of both cattle to pigs and cattle to poultry [67]. The conclusion was that there was an accidental cross-contamination of ingredients used for cattle feedstuffs and ruminant protein which was present in the feed mills for use in pig and poultry rations. Crosscontamination between feed intended for pigs or poultry and cattle feed could have occurred at the feedstuff factory, if feed lines for cattle and feed for monogastric species were not distinct, during the transport of feed or on the farm, especially in mixed farms with both cattle and pigs or poultry. The potential for cross-contamination is heightened by the potential for low-dose exposure causing infection; in an oral exposure study it was shown that cattle could become infected by as little as $1 \mathrm{mg}$ of brain homogenate [63]. A statistically significant relationship between the pig density in a region and $\mathrm{BAB}$ cases has also been found in subsequent studies on both the GB data [58] and for other countries including Northern Ireland, France, Switzerland, and Spain [1, 3, 26, 30, 55], supporting this initial hypothesis of cross-contamination of cattle feed with feed intended for pigs, and possibly poultry; a spatial study on feed factories confirmed recently the use of MBM in monogastric feed as a risk factor for BSE [51]. Further evidence on the BAB cases arising from the feedborne source has been provided by Sheridan et al. [57], where a spatial relationship between feed-producers and BSE cases was found. Recently, a case-control study [42] evidenced the use of feed from feedstuff factories fed to young cattle as well as the existence of poultry operation in the farm, if using compound feed, as risk factors for BSE, and thus reinforced the role of compound feed in the risk of BSE.

The removal of specified risk material (SRM), which would contain the most in- fectious material from cattle carcasses, from MBM included in pig and poultry feed, has not been found to completely remove the feedborne risk of exposure. Ducrot et al. [34] found that cases born after such a ban in France (BASBs) had a similar spatial distribution to BAB cases, suggesting a common source of infection. Similarly, Schwermer et al. [55] found that the feedborne source was the most likely route of infection for cases born after an SRM ban in MBM (BAB96), although they considered imported feed or feed ingredients as the most likely source of contaminated feed in Switzerland. The lack of complete effectiveness of the SRM ban is likely to be due to the difficulties of complete removal of some tissues, and the possibility of residual risk in production plants from earlier periods. In Germany, the main routes of transmission have been considered to be cross-contaminated ruminant concentrate feeds and milk replacers, which contained animal fat [19]. In Bavaria, 60-75\% of ruminant feed samples taken between 1996 and 2000 were contaminated with animal material [19] and this contamination could have led to exposure to BSE of ruminants. In Germany, milk replacers could legally contain animal-derived fats until 2000, and it is possible that either infectious material survived the rendering process or that infectious material entered milk replacers through the use of unrefined fats, which were used in milk replacers in Germany [43]. Pottgiesser et al. [52] have also shown a possible association of the feeding of milk replacers with BSE infection in the Schleswig-Holstein region of Germany; the use of milk replacer was also found to be a risk factor in France [42], and they have been suggested as a potential route of infection in Denmark, where Paisley and Hostrup-Pedersen [50] showed that tallow-based milk replacers could have been responsible for all seven cases of BSE in this country. However, there is no experimental evidence to show that tallow from an infected cow contains infectivity, and so the link between milk replacers and BSE infection remains a hypothesis.

BSE cases have continued to occur in the UK after a ban on feeding any MBM to farm 
animals, which would have prevented crosscontamination of MBM between monogastric animals and cattle feeds. A preliminary epidemiological analysis of the first 16 cases born in the UK after the imposition of this ban found a spatial homogeneity of the risk and hypothesized that the most likely source of infection was the importation of feed ingredients that were contaminated with the BSE agent [69]. There was potential for this cross-contamination to occur during mechanical handling, storage and transport of feed ingredients imported into the UK with mammalian MBM legitimately imported for other purposes. Exposure from an environmental non-feed source was considered unlikely due to the absence of previous clinical cases on four of the affected farms [69].

In conclusion, epidemiological evidence across several countries suggests that the feedborne source related to MBM is the only substantiated route of infection, while it is not possible to exclude maternal transmission or milk replacers as a source of some infections. The majority, if not all, of the cases born after the ban on MBM in ruminant feed have arisen due to continued exposure to contaminated feed.

\section{CONTROL MEASURES AND EVOLUTION OF THE BSE EPIDEMICS}

\subsection{Evolvement of control measures}

The history of the BSE epidemic has provided a considerable amount of information on the efficacy of control measures for BSE. After detecting the first BSE case, it took the UK less than two years (i.e., less than half of the incubation period) to realise that there was a major new infection in their cattle population, and to identify the major route of transmission. In the summer of 1988 the first ban on the use of ruminant MBM in ruminant feed was introduced, soon followed by a specified risk material/specified bovine offal (SRM/SBO) ban in September 1990. This led to a continuously decreasing infection pressure in the birth cohorts since autumn 1988. Two conclusions can be drawn from this. Firstly this leads to the conclusion that these initial control measures were sufficient to control the epidemic, even if not fully efficient; i.e., the transmission was reduced sufficiently for the number of infections in subsequent birth cohorts to fall. Secondly, BSE mainly infects the young stock, otherwise the effect on the 1988 cohort could not have been so pronounced, as earlier cohorts would also have been affected. In mainland Europe an understanding of the risk of infection through MBM was learned with some delay, but imports of MBM from the UK were soon considered an important risk factor after BSE cases were found in Switzerland. Individual countries did implement control measures to limit the imports and use of MBM for ruminants, and EU-wide ban on the use of mammalian MBM for ruminants was implemented in 1994, although enforcement of this ban was clearly a problem in several countries.

In 1996 the first article on the zoonotic aspect of BSE was published [70], followed by publications estimating the possible size of the human epidemic as a result of the exposure to BSE. Given the limited data at that time, and the uncertainty in the human incubation period and the effect of the SBO ban (implemented for human food in the UK in 1988), the predicted size of the epidemic varied significantly and included predictions that 100000 UK citizens could be infected by BSE and would develop the disease within 20 years time [21], while others predicted less than one million [36]. The resulting crisis amongst consumers caused further inspection of control measures and a study of the compliance. The UK extended their ruminant feed ban, to further restrict possibilities for crosscontamination in feed production, in an attempt to completely halt further transmission. In the meantime, research showed that rendering systems can reduce the infectious level in MBM, if they apply pressurized cooking at sufficiently high temperature [54]. However, this measure does not remove all infectivity; it only reduces the infectious load in the material up to a thousand times, whereas the systems applied in the UK in the 1980s were considered to reduce the infectious load by at most a factor 10. The EU implemented the batch process $\left(133{ }^{\circ} \mathrm{C}\right.$ at 3 bars during $20 \mathrm{~min}$ ) as a standard for rendering systems in 1996, but 
implementation was slow in some member states due to practical problems and failure to see BSE as a domestic problem.

BSE cases still occurred in the UK after the implementation of the ban on the feeding of mammalian MBM for all farmed animals, known as cases that were born after the reinforced ban (BARBs). While it was evident that the number of cases in the BARB cohorts in the UK had declined as a result of this control measure, the continued occurrence of these cases led to such pressure on policy within the UK and the EU, that in January 2001 the EU also implemented a total ban on the use of MBM to all farmed animals, as well as a ban on other by-products.

\subsection{Evolution of the BSE epidemic analysed from modelling and age of cases}

During the BSE epidemic new control measures were introduced regularly, and only a few minor aspects of the measures were later lifted due to being considered ineffective. The effect of BSE control measures can be seen from the surveillance data by studying the age distribution per test year and per birth cohort. First of all, it can be shown that the mean age of BSE cases per test year increases over time, which is a direct result of the extended control measures. Each set of control measures leads to a specific transmission level of the infection. The number of new cases resulting from an initial infection can be expressed in the basic reproduction ratio, $R_{0}$, [24]. A $R_{0}$ of 1 tells us that one infected animal gives rise to (on average) one new infected animal. When the $R_{0}$ is above 1 , each new infection results in more than one infection so the epidemic increases. Similarly, a $R_{0}$ below 1 is linked to a decrease of an epidemic.

Each value of $R_{0}$ induces a specific age distribution of the cases in a test year [25]. This knowledge can be used to evaluate the effect of control measures and to compare the progress of the epidemic in various countries. Obviously this aspect is influenced by the age distribution of the cattle population; however, by comparing the age distribution of cases per test year to the age distribution per birth cohort, this aspect becomes irrelevant. If the age distribution of cases per cohort is equal to the age distribution of cases per test year, then it can be concluded that the epidemic is not growing, nor declining $\left(R_{0} \approx 1\right)$. When the age distribution of the cases per test year is showing a greater tendency for younger cases than the age distribution per birth cohort, then it can be concluded that the epidemic is still growing $\left(R_{0}>1\right)$, and vice versa. This is explained in more detail by de Koeijer et al. [25].

Due to this effect, the analysis of the average age of the cases year after year is simple and gives an indication of the trend of the epidemic [53]. Roughly, if the average age is increasing, it corresponds to a decreasing $R_{0}$, and when the average age of the cases per test year is higher than the average age in a cohort, that means that $R_{0}<1$, i.e., a declining of exposure over time. The method and the conclusions are straightforward if the assumptions are correct (e.g., steady values for surveillance and age dependant culling of the cattle population, age at infection and incubation period). The average age of BSE cases is increasing over time in most European countries (Tab. II), which reflects their improving BSE control systems over the years. There is a delay in the appearance of this pattern due to the long incubation period of BSE and its large variance; we can see from the UK data that the effect of the control measures from 1988 and 1989 led to an increasing average age of the BSE cases from year 1991 onwards. We can see the age distribution of the cases stabilize around 1993 but it soon increases further due to extra control measures implemented during the 1990s.

The mechanistic models that describe the BSE epidemic rely heavily on the assumptions made, of which a number cannot be validated by an external measure for BSE (e.g., distribution of the age at infection, or level of surveillance in the past). However, they provide estimates of the effect of missing data (e.g., cattle still alive), prevalence and past transmission risk, and can therefore quantify the effect of control measures. The $R_{0}$ approach [24] was applied to British, Dutch, and Swiss data [55], and showed the effect of the ban of MBM to ruminants, and more 
interestingly provided evidence for an external infection source (imports of MBM) that was not considered in the model, and which is therefore to be investigated separately.

\subsection{Evolution of the BSE prevalence over years}

Having the best unbiased estimate of the prevalence of BSE and its trend in time is of the highest importance for risk managers to assess the efficiency of control measures and also to contribute to the evaluation of the risk for animals and humans. The crude analysis of the figures of the BSE epidemics shows huge differences between countries. By 2007, BSE had been detected in 25 countries, the number of cases per country ranging from 1 to more than 180000 cases $^{13}$. When considering the ten most affected countries (Tab. II and Fig. 2), the pattern of the epidemic differs dramatically between countries. The strong differences in the number of cases and the prevalence rate may reflect large differences in the level of exposure of the cattle population and the efficiency of control measures in the different countries (it also relates to variations of the level of surveillance in Europe before 2001). Also, the differences in the year of detection of the first case and the year of the peak evoke variable time-dependent exposure patterns. But above all, from a simple look at the figures, data suggests that the epidemic is now under control, at least in countries which have experienced the disease, taken stringent measures of control and seriously monitored the disease.

Beyond the crude analysis of figures, it is difficult to estimate precisely the size and trend of the epidemic in any country without knowledge of the characteristics of the disease, the demographic parameters of the cattle population, and the performances of the current diagnostic methods. The age at which the disease becomes detectable is higher than the age at which most animals die or are slaughtered, the time from infection to detection is poorly documented, and there is no diagnostic test on live cattle so far. Moreover, until 2001 in the EU and still now in most other countries of the

\footnotetext{
${ }^{13}$ http://www.oie.int/eng/info/en_esbmonde.htm [consulted 2 April 2007].
}

world, the incidence was/is heavily underestimated without active surveillance programs carried out on sufficient sample sizes. Even in EU countries having implemented a compulsory testing at fallen stock and slaughter since 2001, the hindsight is still limited and hampers the estimate of the recent trend of the disease; none of the birth cohorts has been completely tested after six years of exhaustive testing. A correct assessment of the prevalence and its trend needs to take into account all these parameters. Different methods have been applied, from the statistical analysis of surveillance data including logistic regressions and Age-Period-Cohort (APC) models, to mathematical modelling of surveillance data including back-calculation models and $R_{0}$ approaches (see previous paragraph).

The statistical analysis of the surveillance data using logistic regression is relevant when comparing a few successive birth cohorts during a period in which the surveillance is considered to be steady, and gives estimates of the trend of prevalence from one birth cohort to the next (odds ratios which can be considered as relative risks due to the low prevalence). This method was applied to French data [45] and provided evidence of a major decrease of the exposure between birth cohorts 94-95 and 95-96 for slaughtered animals $(\mathrm{OR}=0.46$, 95\% CI 0.27-0.78). If the assumption of a steady surveillance is not fulfilled, the changes in the surveillance must be taken into account, which is possible using an APC model. Based on logistic or Poisson regression, it allows the estimation of the trend of prevalence (the cohort factor) taking into account the age of cases and the year of detection (the period factor). Applied to Swiss data, the APC model identified a major drop of incidence after birth cohort Oct. 89-Mar. 90, which was interpreted as the effect of the feed ban of 1990, and then a second but less important incidence peak for birth cohort Apr.-Sept. 94, which could be the result of cross contamination with contaminated feed dedicated to non-ruminant species [20]. These statistical models, logistic regression and APC models enable other variables that are linked to the prevalence to be taken into account, such as the production 


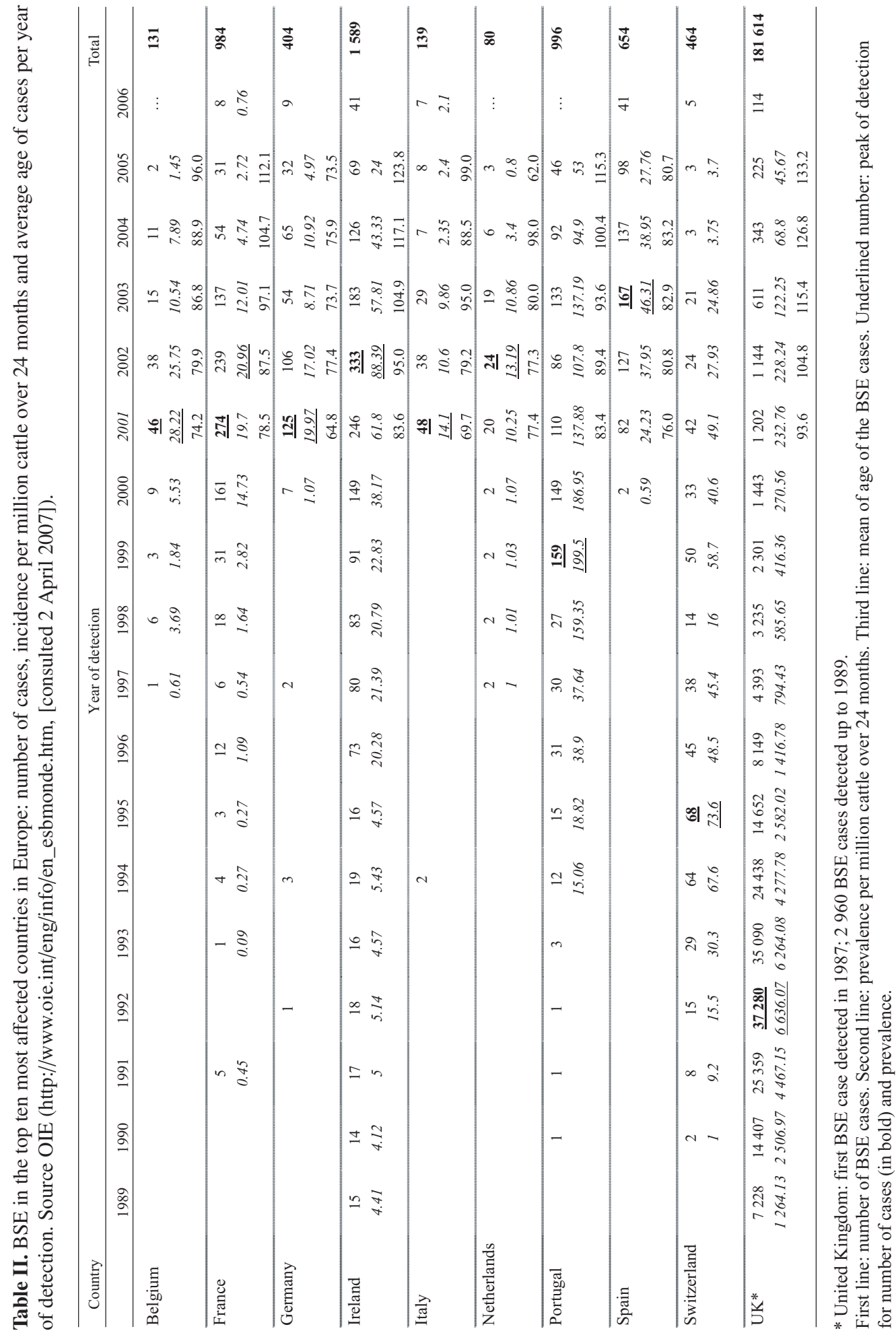


a. Countries with the highest incidences

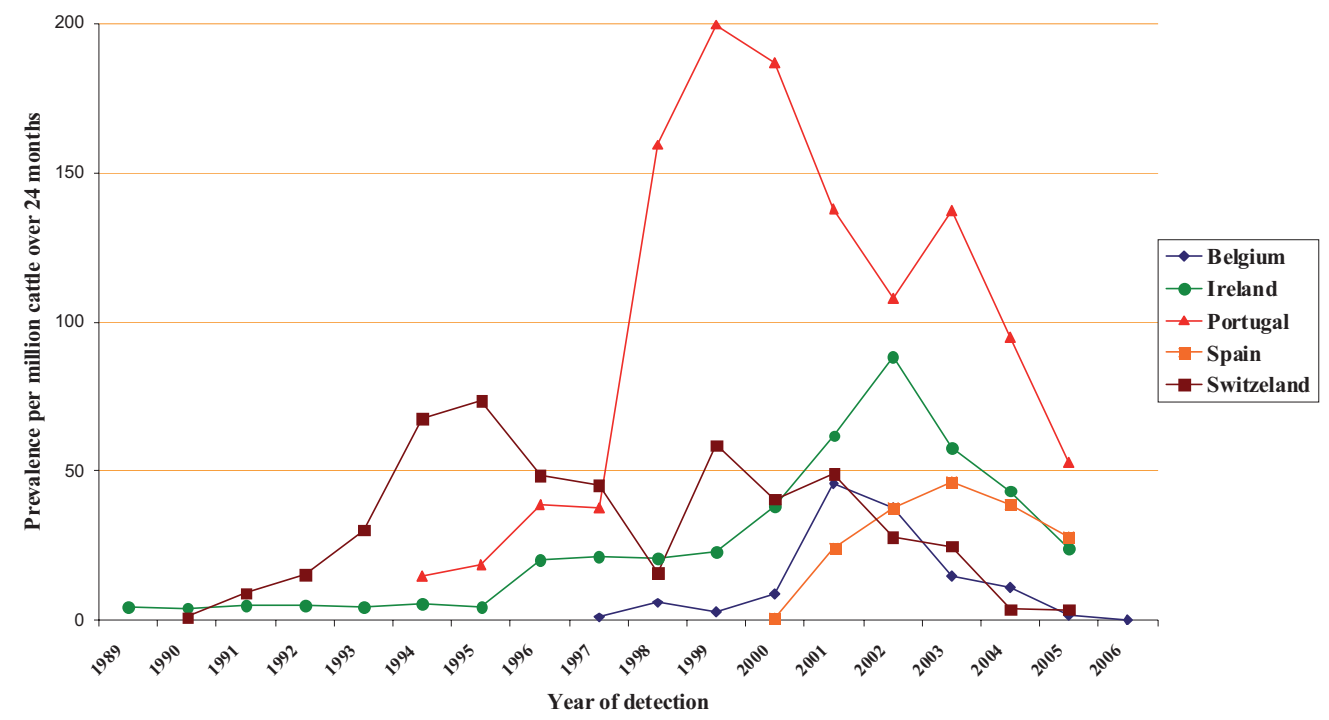

b. Countries with the lowest incidences

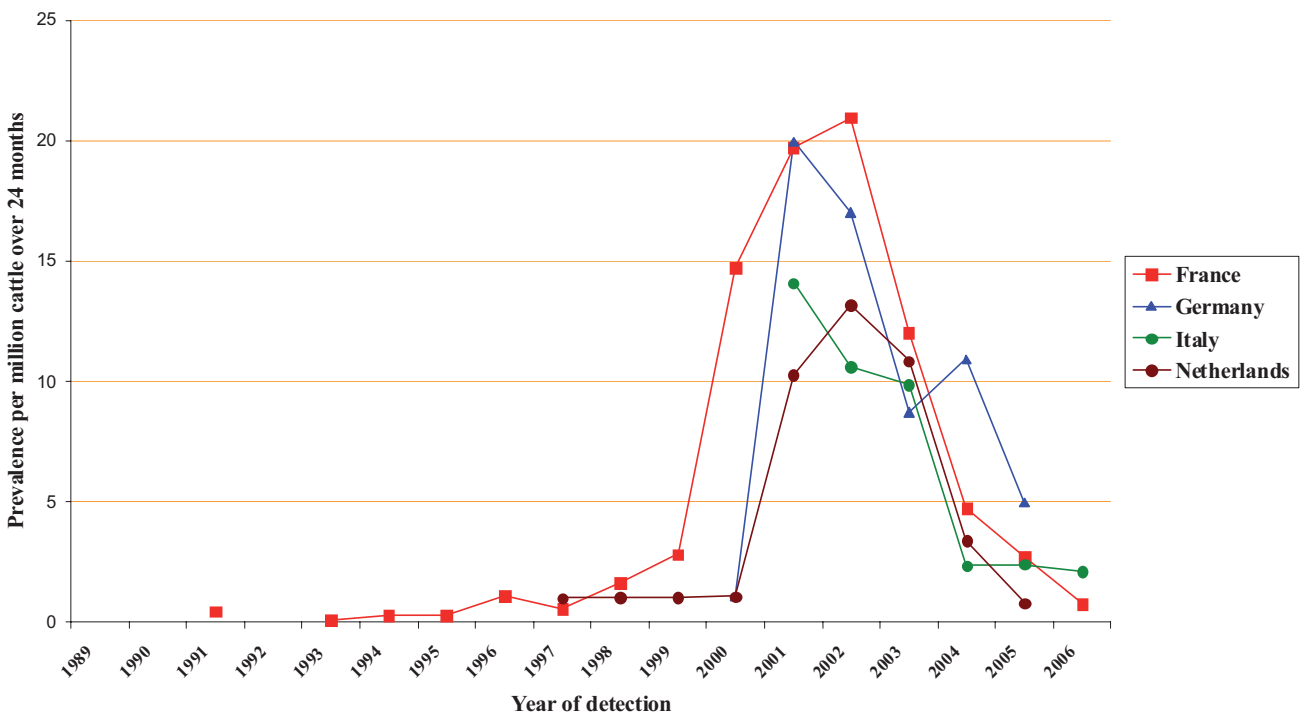

Figure 2. BSE trend in the top ten most affected countries in Europe (UK excluded). Incidence (per million cattle over 24 months) from 1989 through 2006. Source OIE (http://www.oie.int/eng/info/en_esbmonde.htm, [consulted 2 April 2007]). 
type [33] or the season of birth ${ }^{12}$, and then remove these confounders in the estimate of the trend of prevalence. The major drawback of APC model is that the three factors are linearly linked. It is therefore over-parametrized and need further assumptions to disentangle the three factors (e.g., equalizing arbitrarily certain parameters or assuming a function for the level of surveillance over time). Backcalculation models have been used on the same data [60] and gave results consistent with the statistical analysis [16].

\section{ATYPICAL BSES AND THEIR EPIDEMIOLOGICAL MEANING}

The huge increase of the BSE active surveillance programs in Europe, Northern America, and Japan, and the refinement of the diagnostic methods, mainly the biochemical ones, led to the identification at the dawn of the third millennium of two novel forms of TSEs in cattle, named atypical BSEs. BSE has long been considered to be a disease caused by a unique infectious agent. In particular, $\mathrm{PrP}^{\text {res }}$ associated with the disease showed unique biochemical features in cattle whatever the country of origin of the case, as well as after experimental transmission to rodent models or natural transmission to other species including humans. However, recent studies reported cases in cattle showing different $\mathrm{PrP}^{\text {res }}$ features when compared to classical BSE. These cases are of two different types: (i) a H-type that was first described in France [9], characterized by a higher apparent molecular mass of unglycosylated PrPres; (ii) a bovine amyloid spongiform encephalopathy (BASE) that was first described in Italy on two animals [17]. These two cases were able to be more deeply studied, because the entire brain was available, showing significant differences in the distribution of the brain lesions, with the presence of amyloid plaques that led to the proposal of the term BASE. They were characterized by a lower apparent molecular mass of unglycosylated $\mathrm{PrP}^{\mathrm{res}}$ and lower levels of diglycosylated $\mathrm{PrP}^{\mathrm{res}}$, sharing these characteristics with a L-type form described later in other countries. Other biochemical differences char- acterize these atypical forms depending on the antibody used. These two atypical forms can also be differentiated from each other as well as from classical BSE, using Fisher discriminant analysis [49] that specified which antibodies were the most relevant to identify the atypical forms.

The two forms of atypical BSE have been successfully transmitted to rodent models. More precisely, transmission of H-type in wild-type mice (C57B16) showed that the molecular features were maintained in mice [7], and transmission of H-type in transgenic mice expressing bovine or ovine $\mathrm{PrP}$ showed features clearly distinct from that of classical BSE as well as sheep scrapie isolates passaged in these models so far [8]. Transmission of L-type in other bovine PrP transgenic mice led to an incubation period significantly shorter than that found with classical BSE and showing distinct biochemical characteristics [14]. Experimental transmission of the two types to cattle has been initiated recently ${ }^{14}$ and results will be of the utmost interest.

Cases of atypical BSE have only been found in countries having implemented large active surveillance programs. As of 1st September 2007, 36 cases (16 H, 20 L) have been described all over the world in cattle: Belgium (1 L) [23], Canada $(1 \mathrm{H})^{15}$, Denmark $(1 \mathrm{~L})^{16}$, France $(8 \mathrm{H}, 6 \mathrm{~L})^{17}$, Germany $(1 \mathrm{H}, 1 \mathrm{~L})$ [13], Italy $(3 \mathrm{~L})^{18}$, Japan (1 L) [71], Netherlands $(1 \mathrm{H}, 2 \mathrm{~L})^{19}$, Poland $(1 \mathrm{H}, 6 \mathrm{~L})^{20}$, Sweden

\footnotetext{
${ }^{14}$ Buschmann A., Gretzschel A., Biacabe A.G. et al., Characterization of atypical BSE cases of the H-and L-type in Germany, in Proc. Prion 2006, Strategies, advances and trends towards protection of society, Torino, Italy, 2006, p. 195.

${ }^{15} \mathrm{http}: / /$ www.inspection.gc.ca/english/anima/heasan/ disemala/bseesb/mb2006/6investe.shtml [consulted 2 April 2007].

${ }^{16}$ L. Paisley, personal communication.

${ }^{17}$ A.G. Biacabe, personal communication.

${ }^{18} \mathrm{G}$. Ru, personal communication.

${ }^{19}$ J. Langeveld, personal communication.

${ }^{20} \mathrm{M}$. Polak, personal communication.
} 
$(1 \mathrm{H})^{21}$, United Kingdom $(1 \mathrm{H})^{22}$, and USA $(2 \mathrm{H})^{23}$. Another $\mathrm{H}$-type case has been found in a 19 year old miniature zebu in a zoological park in Switzerland [56]. It is noteworthy that atypical cases have been found in countries that did not experience classical BSE so far, like Sweden, or in which only few cases of classical BSE have been found, like Canada or the USA.

Most of atypical cases have been found in adult and old animals, with the striking exception of the Japanese case aged 23 months, which would be worth deeper investigation ${ }^{8}$. Apart this case, the age of the cases ranged from 6.3 to 18 years, with an average of 11.8 and 11.6 years for $\mathrm{H}$ and L-type forms respectively. However it is very difficult to estimate precisely the age distribution of the atypical cases, because there are very few cases and the search for these cases has been focused retrospectively on the oldest BSE cases, for example in Germany and partly in France. Anyway, when properly investigated, it appears that the atypical cases are significantly more frequent in cattle over eight years ${ }^{24}$. Eighteen atypical cases out of the 35 detected have been found through the abattoir stream of surveillance, and therefore in animals assumed to be healthy, even if it has been demonstrated in France that part of the classical BSE cases detected at the slaughterhouse had shown clinical signs compatible with BSE [18]. The other 19 atypical cases have been detected in fallen stock or in emergency slaughtered animals: four of them have been described as diseased, recumbent or downer cow before death, and three others in France had shown clinical signs compatible with a TSE, according to the retrospective interview of the farmer and veterinarian. This was also the case for the zebu in Switzerland that was precisely monitored before death. Therefore, it seems that at least part

\footnotetext{
${ }^{21}$ Gavier-Widén D., Renstöm L., Nöremark M. et al., Characterization of an atypical type-H BSE case in Sweden, Conference Neuroprion, 2006.

${ }^{22}$ http://www.fwi.co.uk/Articles/2007/03/09/102241/ uks-first-case-of-h-type-bse-confirmed-by-defra. html [Consulted 2 April 2007].

${ }^{23} \mathrm{~J}$. Richt, personal communication.

${ }^{24}$ E. Morignat, personal communication.
}

of the atypical cases could have been clinically affected when detected, but much remains to be looked at in this field. The prevalence of atypical BSE appears to be very low in every country in which cases have been found. For example in France, the search for atypical has been carried out exhaustively on cases detected since 1st January 2003, and only eight atypical cases have been found as of 10th March 2007, for more than 11 million animals tested. However, due to the very low number of cases and bias in the investigation of the atypical cases among test positive animals, it is impossible to compare prevalence between countries.

So far, the origin of these novel forms of TSE remains totally unknown. Several hypotheses have been raised [6], such as a major change of the BSE agent, another source of TSE such as sheep and goat scrapie, or a previously unrecognised form of TSE in cattle; also beyond these hypotheses, the question arises whether these cases are due to exposure to a TSE agent or are a 'spontaneous' form of TSE. Apart from the Japanese case born in 2001, all the cases detected so far were born before the total ban of MBM in feed of farm animals (the year of birth ranged from 1987 to 1999) and therefore it is too early to exclude an exposure through contaminated feed. Considering that the compulsory testing of cattle started in 2001 in Europe, and that atypical BSEs are found in animals aged more than six years, one cannot exclude the possibility of finding cases born after 2001 in the future. And last but not least, similarities of $\mathrm{PrP}^{\mathrm{res}}$ between $\mathrm{H}$ type BSE and human prion diseases like CJD or GSS have been put forward [10], as well as between L-type BSE and CJD [17]. These findings raise questions about the origin and inter species transmission of these prion diseases that were discovered through the BSE active surveillance.

\section{CONCLUSION}

In the last ten years, a considerable amount of active surveillance data has been collected. An important outcome from the analysis of these data for several EU countries, confirming the initial findings in the UK, is the difficulty 
of completely eradicating the risk of feedborne exposure. MBM has still probably been involved in cases born after the ban and reinforced ban of MBM in cattle feed. It has also provided data with which to analyse the trend of the BSE epidemic following control measures. Some other important points arise from these results in terms of surveillance and control of BSE. First of all this overview shows that there are a few control measures which may have a major effect on the control of BSE: (1) restrict MBM in ruminant feed, especially for young cattle; (2) control of cross-contamination between monogastric and ruminant feed; (3) remove the materials with the highest infectious load from food (food safety measure) and feed (BSE control measure); (4) use high temperature pressurized rendering systems (however, UK managed the epidemic without this fourth measure, and it has not been possible to specifically measure its effect on the BSE epidemic from the case data).

Also, there is a simple method to assess the national BSE situation: based on the age distribution of the BSE cases found, one can assess the efficiency of the control system. When the age distribution of BSE cases in a test year is shifted to older ages as it is in the birth cohort distribution, then the epidemic is fading out. Given the present low levels of BSE incidence and the presence of SRM measures for food safety, we can relax under those conditions. However, when the age of the BSE cases is younger than expected, the surveillance should be intensified and a more thorough analysis of the BSE control measures is warranted. This will include the inspection of the imports, especially for those countries that have commercial contacts with countries with higher BSE incidence.

And finally, to substantially reduce transmission for eradication of a present BSE epidemic, a combination of these control measures is needed, but to prevent a new epidemic when import risks are restricted, one could even suffice with only one of these measures, when they are fully enforced, or possibly a combination of two ${ }^{2}$ [24]. This is based on a quantitative analysis that showed that a well enforced control measure should be able to reduce transmission levels or risk by $99 \%$. Given that the worst epidemic of any disease ever seen had a reproduction ratio between 10 and 20 , and the impact of all control measures is more or less linear, this level of reduction should prevent epidemics. However, this does not suffice for eradicating an epidemic which has developed already; and this also assumes that the BSE risk in imports is less than the internal risk of BSE transmission within the country.

\section{REFERENCES}

[1] Abrial D., Calavas D., Jarrige N., Ducrot C., Poultry pig and the risk of BSE following the feed ban in France - a spatial analysis, Vet. Res. (2005) 36:615628.

[2] Abrial D., Calavas D., Jarrige N., Ducrot C., Spatial heterogeneity of the risk of BSE in France following the ban of meat and bone meal in cattle feed, Prev. Vet. Med. (2005) 67:69-82.

[3] Allepuz A., López-Quílez A., Forte A., Fernández G., Casal J., Spatial analysis of bovine spongiform encephalopathy in Galicia, Spain (2000-2005), Prev. Vet. Med. (2007) 79:174-185.

[4] Anderson R.M., Donnelly C.A., Ferguson N.M., Woolhouse M.E.J., Watt C.J., Udy H.J., MaWhinney S., Dunstan S.P., Southwood T.R.E., Wilesmith J.W., Ryan J.B.M., Hoinville L.J., Hillerton J.E., Austin A.R., Wells G.A.H., Transmission dynamics and epidemiology of BSE in British cattle, Nature (1996) 382:779-788.

[5] Anonymous, USDA plans sharp increase in BSE testing, J. Am. Vet. Med. Assoc. (2004) 224:1402.

[6] Baron T., Biacabe A.G., Arsac J.N., Benestad S.L., Groschup M.H., Atypical transmissible spongiform encephalopathies (TSEs) in ruminants, Vaccine (2006) 25:5625-5630.

[7] Baron T., Biacabe A.G., Bencsik A., Langeveld J.P.M., Transmission of new bovine prion to mice, Emerging Infect. Dis. (2006) 12:1125-1128.

[8] Béringue V., Bencsik A., Le Dur A., Reine F., Laï T.L., Chenais N., Tilly G., Biacabe A.G., Baron T., Vilotte J.L., Laude H., Isolation from cattle of a prion strain distinct from that causing bovine spongiform encephalopathy, PloS Pathog. (2006) 2:956-963.

[9] Biacabe A.G., Laplanche J.L., Ryder S.J., Baron T., Distinct molecular phenotypes in bovine prion diseases, EMBO Rep. (2004) 5:110-115.

[10] Biacabe A.G., Jacobs J.G., Bencsik A., Langeveld J.P.M., Baron T., H-Type bovine spongiform encephalopathy - complex molecular features and similarities with human prion diseases, Prion (2007) 1:1-7.

[11] Braun U., Kihm U., Pusterla N., Schomann M., Clinical examination of cattle upon with suspicion of 
bovine spongiform encephalopathy (BSE), Schweiz. Arch. Tierheilkd. (1997) 139:35-41.

[12] Braun U., Schicker E., Hörnlimann B., Diagnostic reliability of clinical signs in cows with suspected bovine spongiform encephalopathy, Vet. Rec. (1998) 143:101-105.

[13] Buschmann A., Biacabe A.G., Ziegler U., Bencsik A., Madec J.Y., Erhardt G., Lühken G., Baron T., Groschup M.H., Atypical scrapie cases in Germany and France are identified by discrepant reaction patterns in BSE rapid tests, J. Virol. Methods (2004) 117:27-36.

[14] Buschmann A., Gretzschel A., Biacabe A.G., Schiebel K., Corona C., Hoffmann C., Eiden M., Baron T., Casalone C., Groschup M.H., Atypical BSE in Germany-proof of transmissibility and biochemical characterization, Vet. Microbiol. (2006) 117:103-116.

[15] Calavas D., Ducrot C., Baron T., Morignat E., Vinard J.L., Biacabe A.G., Madec J.Y., Bencsik A., Debeer S., Eliazsewicz M., Prevalence of BSE in western France by screening cattle at risk: preliminary results of a pilot study, Vet. Rec. (2001) 149:55-56.

[16] Calavas D., Supervie V., Morignat E., Costagliola D., Ducrot C., Complementary approach of data analysis and modelling to estimate the pattern of the BSE epidemic: the example of France, Risk Analysis (2007) 27:1141-1150.

[17] Casalone C., Zanusso G., Acutis P., Ferrari S., Capucci L., Tagliavini F., Monaco S., Caramelli M., Identification of a second bovine amyloidotic spongiform encephalopathy: molecular similarities with sporadic Creutzfeldt-Jakob disease, Proc. Natl. Acad. Sci. USA (2004) 101:3065-3070.

[18] Cazeau G., Ducrot C., Collin E., Desjouis G., Calavas D., Questionnaire analysis of BSE cases in France detected by active surveillance and the reasons for non-notification, Vet. Rec. (2004) 154:133-136.

[19] Clauss M., Sauter-Louis C., Chaher E., Pottgiesser C., Goebel S., Selhorst T., Wichmann H.E., Klee W., Kienzle E., Investigations of the potential risk factors associated with cases of bovine spongiform encephalopathy in Bavaria, Germany, Vet. Rec. (2006) 158:509-513.

[20] Cohen-Sabas C.H., Heim D., Zurbriggen A., Stärk K.D., Age-period-cohort analysis of the bovine spongiform encephalopathy (BSE) epidemic in Switzerland, Prev. Vet. Med. (2004) 66:19-33.

[21] Cousens S.N., Vynnycky E., Zeidler M., Will R.G., Smith P.G., Predicting the CJD epidemic in humans, Nature (1997) 385:197-198.

[22] Cranwell M.P., Hancock R.D., Hindson R.D., Hall S.A., Daniel N.J., Hopkins A.R., Wonnacott B., Vivian M.L., Hunt P.T., Bovine spongiform encephalopathy, Letter, Vet. Rec. (1988) 122:190.

[23] De Bosschere H., Roels S., Vanopdenbosch E., Atypical case of bovine spongiform encephalopathy in an East-Flemish cow in Belgium, Intern. J. Appl. Res. Vet. Med. (2004) 2:52-54.
[24] De Koeijer A., Heesterbeek H., Schreuder B., Oberthür R., Wilesmith J.W., Van Roermund H., De Jong M., Quantifying BSE control by calculating the basic reproduction ratio $R_{0}$ for the infection among cattle, J. Math. Biol. (2004) 48:1-22.

[25] de Koeijer A.A., Schreuder B.E.C., Bouma A.M., Factors that influence the age distribution of BSE cases: potentials for age targetting in surveillance, Livest. Prod. Sci. (2002) 76:223-233.

[26] Denny G.O., Hueston W.D., Epidemiology of bovine spongiform encephalopathy in Northern Ireland 1988 to 1995 , Vet. Rec. (1997) 140:302-306.

[27] Doherr M.G., Oesch B., Moser M., Vandevelde M., Heim D., Targeted surveillance for bovine spongiform encephalopathy, Vet. Rec. (1999) 145:672.

[28] Doherr M.G., Audigé L., Monitoring and surveillance for rare health-related events: a review from the veterinary perspective, Philos. Trans. R. Soc. Lond., B, Biol. Sci. (2001) 356:1097-1106.

[29] Doherr M.G., Heim D., Fatzer R., Cohen C.H., Vandevelde M., Zurbriggen A., Targeted screening of high-risk cattle populations for BSE to augment mandatory reporting of clinical suspects, Prev. Vet. Med. (2001) 51:3-16.

[30] Doherr M.G., Hett A.R., Rufenacht J., Zurbriggen A., Heim D., Geographical clustering of cases of bovine spongiform encephalopathy (BSE) born in Switzerland after the feed ban, Vet. Rec. (2002) 151:467-472.

[31] Donnelly C.A., Ferguson N.M., Ghani A.C., Anderson R.M., Implications of BSE infection screening data for the scale of the British BSE epidemic and current European infection levels, Proc. Biol. Sci. (2002) 269:2179-2190.

[32] Donnelly C.A., Ferguson N.M., Ghani A.C., Woolhouse M.E.J., Watt C.J., Anderson R.M., The epidemiology of BSE in cattle herds in Great Britain. I. Epidemiological processes, demography of cattle and approaches to control by culling, Philos. Trans. R. Soc. Lond., B, Biol. Sci. (1997) 352:781-801.

[33] Ducrot C., Roy P., Morignat E., Baron T., Calavas D., How the surveillance system may bias the results of analytical epidemiological studies on BSE: prevalence among dairy versus beef suckler cattle breeds in France, Vet. Res. (2003) 34:185-192.

[34] Ducrot C., Abrial D., Calavas D., Carpenter T., A spatio-temporal analysis of BSE cases born before and after the reinforced feed ban in France, Vet. Res. (2005) 36:839-853.

[35] Fraser H., Mc Connell I., Wells G.A.H., Dawson M., Transmission of bovine spongiform encephalopathy to mice, Vet. Rec. (1988) 123:472.

[36] Ghani A.C., Ferguson N.M., Donnelly C.A., Hagenaars T.J., Anderson R.M., Epidemiological determinants of the pattern and magnitude of the vCJD epidemic in Great Britain, Proc. R. Soc. Lond., B, Biol. Sci. (1998) 265:2443-2452. 
[37] Griffin J.M., Collins J.D., Nolan J.P., Weavers E.D., Bovine spongiform encephalopathy in the Republic of Ireland: epidemiological observations 1989-1996, Ir. Vet. J. (1997) 50:593-600.

[38] Heim D., Wilesmith J.W., Surveillance of BSE, Arch. Virol. (2000) 16:127-133.

[39] Hoinville L.J., Wilesmith J.W., Richards M.S., An investigation of risk factors for cases of bovine spongiform encephalopathy born after the introduction of the feed ban, Vet. Rec. (1995) 136:312-318.

[40] Hoinville L.J., A review of the epidemiology of scrapie in sheep, Rev. - Off. Int. Epizoot. (1996) 15:827-852.

[41] Jarrige N., Ducrot C., Lafon D., Thiebot B., Calavas D., Potential sources of infection for BSE cases born in France after 1996, Vet. Rec. (2006) 159:285-286.

[42] Jarrige N., Ducrot C., Cazeau G., Morignat E., La Bonnardière C., Calavas D., Case-control study on risk factors for BSE cases born after the feed ban in France, Vet. Res. (2007) 38:505-516.

[43] Kamphues J., Zentek J., Oberthur R.C., Flachowsky G., Coenen M., Risk assessment for animal derived feedstuffs as vectors for bovine spongiform encephalopathy (BSE) in Germany. Part I: Comparative risk assessment for animal derived feedstuffs, Dtsch. Tierarztl. Wochenschr. (2001) 108:283-290.

[44] Konold T., Sivam S.K., Ryan J., Gubbins S., Laven R., Howe M.J.H., Analysis of clinical signs associated with bovine spongiform encephalopathy in casualty slaughter cattle, Vet. J. (2006) 171:438-444.

[45] La Bonnardière C., Calavas D., Abrial D., Morignat E., Ducrot C., Estimating the trend of the French BSE epidemic over six birth cohorts through the analysis of the abattoir screening in 2001 and 2002, Vet. Res. (2004) 35:299-308.

[46] La Bonnardière C., Bonaiti B., Abrial D., Gasqui P., Calavas D., Ducrot C., Barnouin J., Milk yield, age at first calving, and the risk of BSE: an analysis at the farm level in France, Prev. Vet. Med. (2007) 78:67-78.

[47] Morignat E., Ducrot C., Roy P., Baron T., Vinard J.L., Biacabe A.G., Madec J.Y., Bencsik A., Debeer S., Eliazsewicz M., Calavas D., Targeted surveillance to assess the prevalence of BSE in high-risk populations in western France and the associated risk factors, Vet. Rec. (2002) 151:73-77.

[48] Morignat E., Ducrot C., Roy P., Cohen C., Calavas D., Prevalence of BSE in cattle found dead euthanased or emergency slaughtered on farms in western France in 2000-2001 and 2002, Vet. Rec. (2004) 155:481486.

[49] Morignat E., Biacabe A.G., Ducrot C., Baron T., Calavas D., Typologie des phénotypes biochimiques de l'ESB par analyse discriminante, Epidémiol. Santé Anim. (2006) 49:29-35.

[50] Paisley L.G., Hostrup-Pedersen J., A quantitative assessment of the risk of transmission of bovine spongiform encephalopathy by tallow-based calf milkreplacer, Prev. Vet. Med. (2004) 63:135-149.

[51] Paul M., Abrial D., Jarrige N., Rican S., Garrido M., Calavas D., Ducrot C., Bovine spongiform encephalopathy and spatial analysis of the feed industry, Emerging Infect. Dis. (2007) 13:867-872.

[52] Pottgiesser C., Ovelhey A., Ziller M., Kramer M., Selhorst T., Conraths F.J., Potential risk factors associated with bovine spongiform encephalopathy in cattle from Schleswig-Holstein, Germany, J. Vet. Med. B Infect. Dis. Vet. Public Health (2006) 53:306-311.

[53] Saegerman C., Speybroeck N., Vanopdenbosch E., Wilesmith J.W., Berkvens D., Trends in age at detection in cases of bovine spongiform encephalopathy in Belgium: an indicator of the epidemic curve, Vet. Rec. (2006) 159:583-587.

[54] Schreuder B.E.C., Geertsma R.E., van Keulen L.J.M., van Asten J.A.A.M., Enthoven P., Oberthur R.C., de Koeijer A.A., Osterhaus A.D.M.E., Studies on the efficacy of hyperbaric rendering procedures in inactivating bovine spongiform encephalopathy (BSE) and scrapie agents, Vet. Rec. (1998) 142:474-480.

[55] Schwermer H., Heim D., Cases of bovine spongiform encephalopathy born in Switzerland before and after the ban on the use of bovine specified risk material in feed, Vet. Rec. (2007) 160:73-77.

[56] Seuberlich T., Botteron C., Wenker C., CaféMarçal V., Oevermann A., Haase B., Leeb T., Heim D., Zurbriggen A., Spongiform encephalopathy in a miniature zebu, Emerging Infect. Dis. (2006) 12:1950-1953.

[57] Sheridan H.A., McGrath G., White P., Fallon R., Shoukri M.M., Martin S.W., A temporal-spatial analysis of bovine spongiform encephalopathy in Irish cattle herds, from 1996 to 2000, Can. J. Vet. Res. (2005) 69:19-25.

[58] Stevenson M.A., Morris R.S., Lawson A.B., Wilesmith J.W., Ryan J.B.M., Jackson R., Area-level risks for BSE in British cattle before and after the July 1988 meat and bone meal feed ban, Prev. Vet. Med. (2005) 69:129-144.

[59] Sugiura K., Adjusted incidence risks of BSE in risk subpopulations of cattle in Japan, Prev. Vet. Med. (2006) 75:163-176.

[60] Supervie V., Costagliola D., The unrecognised French BSE epidemic, Vet. Res. (2004) 35:349-362.

[61] Thrusfield M.V., Veterinary Epidemiology, Blackwell Science, London, UK, 1996.

[62] Wells G.A.H., Scott A.C., Johnson C.T., Gunning R.F., Hancock R.D., Jeffrey M., Dawson M., Bradley R., A novel progressive spongiform encephalopathy in cattle, Vet. Rec. (1987) 121:419-420.

[63] Wells G.A.H., Konold T., Arnold M.E., Austin A.R., Hawkins S.A.C., Stack M., Simmons M.M., Lee Y.H., Gavier-Widén D., Dawson M., Wilesmith J.W., Bovine spongiform encephalopathy: the effect of oral exposure dose on attack rate and incubation period in cattle, J. Gen. Virol. (2007) 88:1363-1373. 
[64] Wilesmith J.W., Wells G.A.H., Cranwell M.P., Ryan J.B.M., Bovine spongiform encephalopathy: epidemiological studies, Vet. Rec. (1988) 123:638-644.

[65] Wilesmith J.W., Ryan J.B.M., Atkinson M.J., Bovine spongiform encephalopathy: epidemiological studies on the origin, Vet. Rec. (1991) 128:199-203.

[66] Wilesmith J.W., Ryan J.B.M., Hueston W.D., Bovine spongiform encephalopathy: case-control studies of calf feeding practices and meat and bone meal inclusion in proprietary concentrates, Res. Vet. Sci. (1992) 52:325-331.

[67] Wilesmith J.W., Recent observations on the epidemiology of bovine spongiform encephalopathy, in: Gibbs C.J. (Ed.), Bovine Spongiform Encephalopathy. The BSE dilemma, Springer Verlag, New York, USA, 1996, pp. 45-55.

[68] Wilesmith J.W., Ryan J.B.M., Stevenson M.A., Morris R.S., Pfeiffer D.U., Lin D., Jackson R., Sanson
R.L., Temporal aspects of the epidemic of bovine spongiform encephalopathy in Great Britain: holdingassociated risk factors for the disease, Vet. Rec. (2000) 147:319-325.

[69] Wilesmith J.W., Preliminary epidemiological analyses of the first 16 cases of BSE born after July 31 1996 in Great Britain, Vet. Rec. (2002) 151:451-452.

[70] Will R.G., Ironside J.W., Zeidler M., Cousens S.N., Estibeiro K., Alperovitch A., Poser S., Pocchiari M., Hofman A., Smith P.G., A new variant of Creutzfeldt-Jakob disease in the UK, Lancet (1996) 347:921-925.

[71] Yamakawa Y., Hagiwara K., Nohtomi K., Nakamura Y., Nishijima M., Higuchi Y., Sato Y., Sata T., Atypical proteinase K-resistant prion protein (PrPres) observed in an apparently healthy 23-monthold Holstein steer, Jpn. J. Infect. Dis. (2003) 56:221222. 